\title{
Contrasting Learner Language in Social Sciences Education: A Case Study at the University of Malaga
}

\author{
Mary Griffith $^{1, *}$, Clotilde Lechuga ${ }^{2}$ \\ ${ }^{1}$ Department of English, French and German, Malaga University, Spain \\ ${ }^{2}$ Department of Mathematics Education, Social Science Education and Experimental Sciences, Malaga University, Spain
}

Copyright $(\mathrm{C} 2018$ by authors, all rights reserved. Authors agree that this article remains permanently open access under the terms of the Creative Commons Attribution License 4.0 International License

\begin{abstract}
This paper presents specific reference tools to provide institutional language integrated support with a specific language plan for a bilingual programme at the University of Malaga. This follows experts' opinions that claim the need of such a plan. While studies show the importance of language support in bilingual instruction, they rarely address specific content professors' needs tending to remain distant from real teaching contexts. The title "The language of learning" highlights the reality of bilingual classrooms to address specific needs of this unique academic scenario. The article examines how language support has a dual focus that includes both students and instructors. The paper concludes with a reflection on interdisciplinary innovation projects that provide professors with the tools to ensure the quality of bilingual programmes.
\end{abstract}

Keywords English Medium Instruction, Language Acquisition, Higher Education, Social Sciences Education, Gender art

\section{Introduction}

This paper presents specific reference tools which continues the line started on the article published in 2 nd International Conference on Higher Education Advances (HEAD '16) (Barrios, López-Gutiérrez \& Lechuga, 2016), where we found that neither institutional language integrated support nor a specific language plan was being provided by the bilingual programme. This runs counter to experts' opinion calling for the need of such a plan: "The English-taught degree programme requires a language plan of its own, which will be complementary to the larger university policy and plan...; it is a necessity for ensuring a smooth and collaborative transition into English medium" (Marsh et al., 2013, p. 15). While studies show the importance of language support in bilingual instruction, they rarely address specific content professors' needs, tending to remain distant from real teaching contexts. The educational Innovation Project (PIE 15-100) has provided professional development for subjects taught through the medium of English in the Primary Education degree at the University of Málaga and will be showcased in this article.

The main project objectives and associated actions may be summed up along the following three lines: first, professional development for effective instruction through English, next, language provision, support and resources, and finally, monitoring and evaluation of the experience. As a follow-up, we present a specific case study to illustrate how language support and monitoring works in practice.

First, the paper acknowledges a trend towards English Medium Instruction (EMI) in Higher Education while at the same time it distinguishes English Medium Instruction (EMI) from adjunct CLIL (Brinton, Snow \& Wesche, 2011) suggesting that more explicit language integration is needed. With this in mind, we present a professional development project for instructors which we will call the CLIL eye (Griffith, 2017). Secondly, we examine how language support has a dual focus that includes both students and instructors. Outlining these actions, the innovation project focuses on collaborative work, language support, and collective training in aspects related to a systematic monitoring of the experience. Finally, we will use a case study in which a glossary is integrated into a lecture and an external observer will provide assessment for the instructor on ways to improve discourse. The results indicate how, with this task design, language is supported as not only the language of learning, and as language through learning (Coyle, et al., 2010), but more specifically as the language for teaching. The paper concludes with a reflection on interdisciplinary innovation projects that provide professors with the tools they need to ensure the quality of bilingual programmes.

The background of any discussion on plurilingualism in higher education in Europe begins with convergence. In 
Paris in 1998, European universities highlighted the need to create greater plurilingualism in Europe (Sorbonne Joint Declaration, Paris, 25/5/1998). After about a decade, Smit and Dafouz (2012) have reported "English medium university courses all over continental Europe have tripled" (p.2). In Spain, Dafouz and Nuñez (2009) have cited more than thirty higher educational institutions offering bilingual degrees. Our study takes place at the University of Málaga in southern Spain and explores how a language specialist can assist content professors teaching through a second language.

In our search for usefulness, and in order to be as concrete as possible, we will share our initial prediction and research purpose set into the higher educational context. "Most teachers have not yet acquired the teaching competencies and abilities that are peculiar to CLIL [Content and Language Integrated Learning]. They have been unable to do so because broadly speaking suitable Teacher Education (TED) in CLIL is not offered in a systematic fashion" (Horrillo, 2012, p. 4). Quality seems to be something taken for granted and specific methodological training is rarely addressed at the university level.

In many countries the educational infrastructure does not support quality EMI provision: there is a shortage of linguistically qualified teachers; there are no stated expectations of English language proficiency; there appear to be few organisational or pedagogical guidelines which might lead to effective EMI teaching and learning; there is little or no EMI content in initial teacher education (teacher preparation) programmes and continuing professional development (in-service) courses. (Deardon 2014, 2)

We predicted university professors outside language areas would benefit from a CLIL/EMI practicum; and we explored how to do this from multiple perspectives. Exploratory does not mean without purpose or without direction, rather what it means is that the project tended to work inductively from the bottom up rather than deductively. In the case of this article the discussion will be focused on language support strategies for students as well as their content instructor's language performance.

Linguists find it easy to believe in bilingualism, but many content professors find themselves uncomfortable in this new found role of language expert as corroborated by Hynninen (2012). We insist that, through a facilitative collaboration, professional development can impact teaching practice in higher education. Collaboration gives all involved a unique opportunity to learn from the other. Thus, our inquiry began by establishing a dialogue between a language specialist and a content specialist. In the next section we will point to the context, clarify terminology and in turn, reveal the research focus that surged out of the study.

This paper discusses relevant challenges facing bilingual instruction in our specific context. This collaborative initiative allows the content instructor to discover ways to improve teaching first by directing student discourse what Coyle et al, (2010) identify as the 'language of learning' and next by directing instructional discourse with what we describe as the 'language for teaching'.

\subsection{Context}

English Medium Instruction (EMI) has been a growing trend across universities in Europe in the last 15 years. This movement was first introduced in Master's degree programmes although it has progressively extended to bachelor's programmes (Wächter \& Maiworm, 2008). Not only is EMI a direct result of globalisation in Europe and elsewhere, but it also currently lies at the center of internationalisation strategies of many tertiary institutions around the globe (Doiz et al., 2013; Gustafsson \& Jacobs, 2013; Wilkinson, 2013). Many factors contribute to this need such as the promotion of job mobility, employability, staff and student exchanges and joint- and double-degrees substantiate the case for English-taught degree courses (Fortanet, 2008).

However, the first challenge is in the definition of EMI. EMI in its strictest definition implies that language learning is implicit and not explicit. Airey (2012) goes so far as to insist that he is does not teach English while lecturing on Physics through the medium of English. So perhaps a clarification in terminology is in order. Brinton, et al. (2011) has identified three types of language integrated learning in higher education. First, theme based CLIL where language instructors explicitly focus language by using contents. In the past this has been identified as English for Specific purposes (ESP) or a topic based approach. Second, these authors point to sheltered CLIL, where a focused content approach allows for only implicit language learning. This is indeed EMI across Europe, particularly in higher education. And finally they cite adjunct CLIL, which allows for a content focus as well as integrating language. Given this clarification, our approach clearly takes the adjunct approach in that language support is explicitly provided to both students as well as to instructors.

Many authors choose to use the term Integrated Content and Language in Higher Education (ICLHE) over the umbrella term Content and Language Integrated Learning (CLIL) since, as Gustafsson and Jacobs (2013) argue, this latter term is originally linked to school -rather than to university-contexts and "there are issues peculiar to higher education, such as disciplinarity, which make this CLIL approach distinctly different in the higher education context" (p. iii). For the purposes of this paper, we will use them interchangeably, but clearly point to the higher educational context as being specific to our research or more specifically adjunct CLIL (Brinton, et al. 2011).

In the case of the Faculty of Education, at the University of Málaga a group in the Bachelor's Degree in Primary Education has been partly taught through the medium of English since the academic year 2014-2015. On the whole, 
the evaluation of the experience by students and teachers has uncovered new challenges that have been addressed by an interdisciplinary innovation project with the goal of constantly improving the teaching/learning experience. After the first year, the assessment revealed that both students and instructors needed to improve language performance. How to tackle this dilemma will be the focus of this article.

During academic year (2016-2017) an innovative approach took place whereby language support has been addressed in two directions. For students, an integrated glossary has been offered as a tool to explicitly focus technical art terms during a lecture given by a guest professor who belongs to the bilingual team, in the subject Artistic and Visual Education. At the same time, an external observer has evaluated instructor discourse and effectively offered vital feedback to improve teaching discourse. Clearly the language of learning overlaps with the language of teaching and when non-natives are teaching to non-natives, this becomes significant.

\section{Literature Review}

Research has shown "that there is an urgent need for a research-driven approach which consults key stake-holders at a national and international level and which measures the complex processes involved in EMI and the effects of EMI both on the learning of academic subjects and on the acquisition of English proficiency" (Deardon, 2014, 2). The eternal dilemma is finding specialists with both content and foreign language skills and collaboration seems to tacitly be the answer. Gajo (2007) has argued that teacher training must prepare instructors in bilingual didactics, which are different from traditional second language classes and different from traditional content classes.

In similar Spanish university contexts, both Rubio and Hermosín (2010) and Fortanet-Gomez (2012) have examined professors' attitudes toward CLIL instruction. Rubio and Hermosín (2010) explored the "willingness of teachers and students to a hypothetical implementation of multilingualism in a Spanish university." Their results at the University of Huelva demonstrate that over $50 \%$ of their sample would be willing to participate in such a program (Rubio \& Hermosín, 2010, p. 107). This article will provide a snapshot into the university classroom where language is explicitly supported through collaboration.

Fortanet-Gomez's (2012) study in Castellon provides a more varied sample of professor participants. Her main conclusions about higher education show that $72.9 \%$ of professors feel that if they teach in English that this should include language objectives. Her study showed that $95.5 \%$ feel they should receive specific teacher training and $83.8 \%$ think content teachers should coordinate with language teachers (Fortanet-Gomez, 2012, p. 58). She is not alone in this proposal.
Instructors' willingness to grow professionally through this project cannot be underestimated. Clearly, quality instruction begins and ends with quality instructors and the success of every educational programme can be improved with specific teacher support networks. In the case of this project, the language specialist moved into areas of education and art to explore real content specialist's needs. By bringing language learning theories directly into the context of these content classrooms, it was easier to put theories into practice.

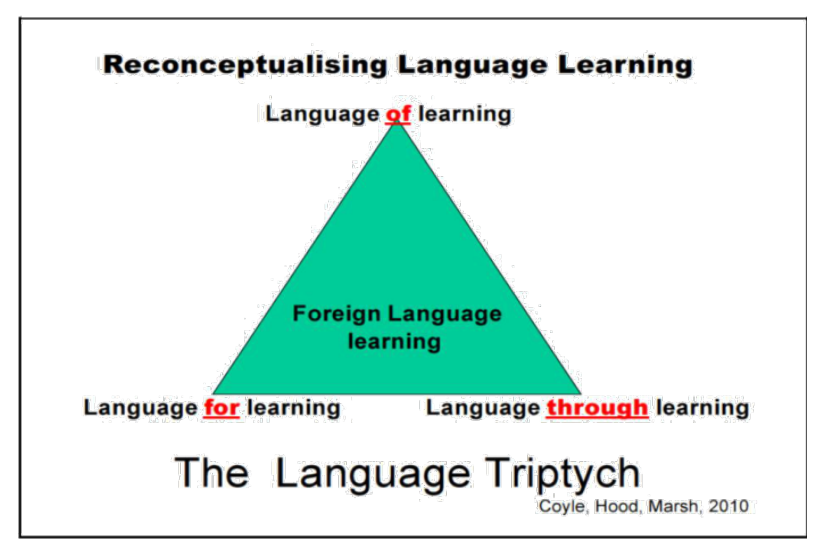

Figure 1. The language triptych as presented by Coyle, Hood and Marsh, 2010.

Coyle et al (2010) discuss re-conceptualising language learning where language needs are divided into three groups: The language of learning (vocabulary), the language for learning (discourse strategies) and the language through learning (the ultimate success). (See Fig 1). We present this project in such a way that the instructor is both instructor and learner. Language can be supported in many ways and we will focus on just two: One for the students, to support the language of learning and one for the instructors, to support the language for teaching.

In the case of this project we will highlight the language of learning with the integrated glossary. In this way, we will illustrate specific language support for students. The explicit lexical focus will be incorporated in the lecture within the instructional design. At the same time, the external observer will provide both didactic and discursive feedback for the instructor. As a result, quality of the instruction through a second language is reinforced. The feedback uses error analysis and discourse features to aid professors in the communicative process. By highlighting the language for teaching, the feedback is particularly relevant to the context at hand.

Consequently, this collaborative case study will address language support using a highly contextualised classroom experience to illustrate how language can be successfully integrated into content classrooms. Stake (1995) would call this the "bounded context" of our case study. We have chosen one instructor, one classroom experience to highlight how language can be supported in two directions: First, for students through instructional design and second, 
for instructors through in-service assessment.

\section{Method}

In response to challenges and difficulties faced during the early stages of the implementation perceived by students and staff, a collaborative interdisciplinary innovation project was designed. Teaching through English in higher education involves constant assessment because CLIL cannot just be simply imposed by government policy-makers. Action research is about capacitating people to act because they choose to do so; it is about searching for real world solutions. The implication being, of course, that the participants are capacitated to define their world through experience developing a sense of empowerment and competence through action and interaction. The methodological choice of participatory action research will allow us to better address the specific qualitative needs of this particular bilingual programme, but most importantly this method allows for flexibility.

In fact bilingual instruction "is not a fixed concept but one that is evolving as an increasing number of countries adopt it as a system of education" (Deardon 2014, 7). Both top-down and bottom-up perspectives are essential for the success and sustainability of any bilingual programme. Participatory action research purposefully takes a bottom-up approach. Two participatory action research inquiries include:

How can language be explicitly supported for students What are the common errors for instructors?

As previously mentioned, the main project objectives and associated actions may be summed up along the following three lines: first, professional development for effective instruction through English, next, language provision, support and resources, and finally, monitoring and evaluation of the experience. As a follow-up, we present a specific case study to illustrate how language support and monitoring works in practice.

We seek not to quantify, but rather to qualify. Many authors have stated that case studies recognize the complexity and embeddedness of social truths. The rigour of this method in educational practice has been criticised as non-generalisable; however, the method has been widely tested and supported in the literature (Reason and Bradbury, 2001; Denzin, 2006; Castro Garcés and Martínez Granada, 2016) and is undeniably relevant to professional practice. However, we duly note that there are limits to this more open structure. "Case study data, paradoxically, is strong in reality but difficult to organize. In contrast, other research data is often weak in reality but susceptible to ready organization. Case studies are a step to action." (Cohen and Manion, 1989, p. 50)

Case study will allow us to create a professional development project for effective language integration.
This innovative project engages professor participants in collaborative interdisciplinary training and practice to illustrate the multiple perspectives involved in any bilingual programme. Both language and non-language specialists are fully aware that there is a need for teamwork and cooperation and this need has been corroborated in previous tertiary education experiences: "Developing an English-taught degree programme requires coordination and, especially at the outset, more staff collaboration than may be considered essential in a domestic language programme" (Marsh et al., 2013, p. 26). The actions have been discussed in detail in Barrios, López-Gutiérrez and Lechuga, (2016) to achieve the goal of professional development. In the case of this article, we will describe the following two specific actions:

[1] Assisted structured materials development; a consensus has been reached to develop language and content integrated tasks with the assistance of a framework designed to include subtasks, one of which is the integrated glossary.

[2] Formative classroom observation; language specialists observe content teachers teach in English and provide formative feedback within the specific classroom context.

How can we provide language support for both students and instructors? Whenever you have non- native instructors, teaching non-native students, explicit language support must be provided. Both students and teaching staff perceived the need language support in order to improve explicitly language proficiency for this bilingual programme. For students this language support is illustrated with instructional design; while for the instructor, language support is illustrated with the observer's feedback of classroom performance. Each of these will be elaborated upon in the following sections.

\section{Instructional Design for Students}

Examining Coyle, et al. (2010), we see a differentiation between the language of learning (vocabulary) and the language through learning. In fact, language through learning is evidenced by effective language teaching. So in turn, we observe the more contextualized the language, the better the language learning; the more interesting the topic, the better the attention levels. The more language is supported, the easier it is for assessment to separate language and content issues. And we observe that the integrated approach addresses the balance of language and contents that provide for true quality in bilingual programmes. The final aspect is the language for learning and this includes a learner centered approach whereby learners are actively using both complex concepts as well as the second language. 
With regard to materials development, a structured glossary has been integrated into a lecture on contemporary art. The specific language focus was supported throughout the lecture and students were provided a handout that re enforced this new terminology. The conference can be seen at the Faculty of Education Science's YouTube web page (Lechuga, 2016).

This class session was originally conceived for the first course in the Bachelor's Degree in Primary Education and aimed to introduce contemporary art practices and a glossary in English language related to Social Science Education. Both the professor of the course as well as the visiting professor agreed that better language performance from the both students and professors could contribute to better instruction. In order to highlight the lexical items necessary for the lecture for students, selected words were chosen to create a glossary to support a lecture on the differences between traditional paintings and contemporary artwork.

The main topic of the lecture referred to Danto's (2003) study concerning Art evolution. In this study, the author elaborates on the differences between mimesis and reflection. Following Danto's theory, mimesis appears as a possible imitation of reality and reflection is understood as meditation/opinion/criticism, all of which advance contemporary understanding (Lechuga, 2015). This elaboration potentially can create a deeper understanding of art, but the complexity of the ideas expressed called for specific lexical items to be defined and understood by students before and during the lecture. In consequence, an explicit glossary of terms was referred to and expanded upon during the class session to support students' content assimilation. This is a clear illustration of the "Language for learning" (Coyle et al. 2010) whereby language is specifically supported so that students can put this language into use.

\section{Instructional Feedback for Instructors}

In the focalized classroom context, during the same lecture referred to in the previous paragraph, an external language specialist generated feedback for the instructor. Using a rubric developed in a similar project in the Computer Science Department at this same university (Griffith, 2012), the instructor's language performance was assessed. The main variables include pronunciation, usage and discourse together with interactional features for classroom instruction. With this specific language support for the instructor, we have addressed the issue of the language for teaching.

Linguistic and instructional data was collected from spoken performance during classroom instruction. One of the objectives of the innovation project is the monitoring and evaluation of the programme with the aim of detecting areas of improvement. This involves classroom observation including coaching. All non-native instructors feel like learners at the same time they feel the responsibility to effectively transmit their contents. What this means is that professionals are encouraged to continually improve within the inherently imperfect context. Many studies (Rubio \& Hermosín, 2010; Morgado \& Coelho, 2012), show that university professors are reluctant, even anxious, as they face instruction through a language that is not their own. The innovative project aims to monitor instructors to improve the quality of their bilingual programme.

\section{Findings}

Implementation deals with instructional actions and seeks a qualitative assessment of the bilingual programme. Undoubtedly, one factor is student proficiency, but the other is instructor proficiency and this is oftentimes overlooked. Fortanet-Gomez (2012) has noted: "While there is general agreement on the importance of this [second] language, its implementation as a language of instruction does not seem to be so evident. [O]ne of the main factors for the success of [multilingual policies] is the lecturers' proficiency..." (p. 52). Instructors are well aware of this issue and we note that to discuss their role as language learners within their role as language instructors empowers them to improve. In this section we will describe the findings for our two participatory action research inquiries:

How can language be explicitly supported for students? What are the common errors for instructors?

\subsection{How can Language be Supported?}

Careful instructional design forms an essential part of any effective instruction and this becomes even more necessary when teaching through a second language. The classroom seminar is entitled Reflective learning: contemporary art in gender studies and aimed to create a better understanding of evolution in artworks including social and gender issues. First, the language support plan consisted in creating a glossary to introduce the subject, so students would focus on significant descriptions using collaborative learning. Visual Thinking Strategies (VTS) (or teaching through images) used scaffolding methodology based on the image of a painting, drawing, sculpture, video as shown in González-Sanz, Feliu-Torruella \& Cardona Gomez (2017). These descriptions were scaffolded during the session and reviewed at the end to provide a better focus of key concepts.

In relation to specific vocabulary, seventeen slides were shown which combined both vocabulary highlighted in sentences and artwork pictures or links to video recordings. 
The idea is to focus attention on keywords by previously selecting nine concepts related to the history of art. These are: Cultural Heritage, Mimesis, Reflection/Reflexion, White Cube, Contemporary art/Postmodern art, Cultural Intangible Heritage, Gender studies.

Some of these glossary words are directly related to the UNESCO Convention's normative as Cultural Heritage to Cultural Intangible Heritage as well as to the Diversity of Cultural Expressions (UNESCO, 1972, 2003, 2005). Concepts include gender perspectives, Flamenco music, ecology, education or cultural diversity. Purposefully, this approach facilitated a better explanation of global interests in preserving Heritage. Moreover, Gender artworks were introduced by a video performance made by a woman artist in which the precise representation of the young female in Eugène Delacroix's (1830), Liberty Leading the People painting was strongly criticized. Finally, last slide presents the same keywords separately so students can explain in English what they understood about the concepts given and then they are asked to connect them to specific examples in a more explicitly language focused conclusion. Evidently, creating critical thinking begins with creating critical discourse and an integrated glossary contextualized in the classroom provided the ideal setting. Adjunct CLIL allowed for language to be supported within the content classroom in a highly integrated way.

In this section we have examined how language can be supported both conceptually and lexically by using an integrated glossary for students, while in the next section the focus will shift to the instructor. Most integrated instruction in Europe is by non-native instructors for non-native learners, so the quality of instructional discourse must be examined in the next section in order to see this instruction from our dual perspective.

\subsection{What are the Common Errors in Instructional Discourse?}

Fortanet-Gomez (2012) has speculated that "what might be the case is that the lack of experience in teaching in English might have led to relatively low self-confidence in using the language for teaching" (p. 55). In order to further develop the CLIL eye, the instructor agreed that classroom observation proved highly relevant to specific teaching needs.

The main variables include pronunciation, usage and discourse together with interactional features for classroom instruction. Pronunciation was an issue, but never to the point of preventing communication. Vowel quality was challenging as was intonation. One of the main causes of foreign accents is that once learners have established the L1 sounds, they tend to perceive all new sounds in terms of those categories. Consequently, these perceptions leak into their L2 production. We remind readers that we are differentiating accent from mispronunciation.

The most common errors occurred with vowel quality in that English vocalic patterns contain more sounds (14) than Spanish (5) or with the consonant sounds that exist in English, but not in Spanish. Spanish does not have the vowel digraphs: ou, ow, eigh, au, aw, oo and, in particular, the diphthong $/ \partial \mho /$ was oftentimes mispronounced. For example: Moses (in Spanish Moises). What the instructor received was this comment: 'in English this sounds like noses, hoses, poses, closes.. es llana. And the o is /ov/.' This type of constrastive feedback allowed her to accommodate her accent into a target pattern. Another example is with the semi vocalic phoneme /ju:/, for example: in Cubism. Here is the feedback provided: 'The $u$ is semi vocalic.... Like the sound you, news, /kjubizm/.' None of these mispronunciations prove any different than what could be expected from Spanish speakers using English given the phonological contrasts between the two systems. In fact the mispronunciations coincide largely with previous research (Griffith, 2012). We do note, however, that communication was never impaired due to these errors.

Usage and discourse errors will be described in this next section and a sample can be seen in Table 2. Perhaps more than the form focus, the underlying ideas in language learning serve to put content professors' foreign language performance into perspective in their new role as language experts. What is salient here is that the feedback has been created for a non-language specialist. The goal has not been to force linguistic terminology specific that only a language specialist would understand; rather the main aim was to provide meaningful and specific feedback on language performance for this Art History instructor.

Some authors refer to this highly functional L2 usage as "multicompetence" (Cook, 2006). This author has argued L2 learners, including those who have reached the ultimate attainment stage in the L2, are not equivalent of two monolinguals in one brain. Instead, Cook maintained that L2 learners possess an integrated cognitive system, called multicompetence. L2 learners process information in both languages differently from that of monolingual native speakers. The resulting linguistic competence of a bilingual L2 learner is therefore qualitatively different from the one possessed by monolingual minds. Language learners must necessarily be measured in functional terms and not as a deviation from some unattainable ideal. Somehow, content professors are reassured by this idea of functional bilingualism. Developing the CLIL eye for instructors has meant understanding how proper CLIL instruction is not only within the realm of multicompetence, it is also within their reach. 
Table 2. Error analysis

\begin{tabular}{|c|c|c|}
\hline UTTERANCE & CORRECTION & LINGUISTIC COMMENT \\
\hline $\begin{array}{l}\text { Are you agree } \\
\text { that is it a piece of art? }\end{array}$ & $\begin{array}{l}\text { Do you think this is art? } \\
\text { Is this art? Is this a piece of art? } \\
\text { Do you agree that this is art? }\end{array}$ & $\begin{array}{l}\text { Excessive use of } \boldsymbol{i t} \\
\text { Improper use of agree } \\
\text { Review interrogative syntax and embedded } \\
\text { questions }\end{array}$ \\
\hline Do you follow? & Are you following me? & Wrong tense in EN \\
\hline ...Russian by that moment & $\begin{array}{l}\text { At that moment, at that time Usu. refers to a specific } \\
\text { moment } \\
\text { By that time (usually refers to simultaneous actions) } \\
\text { by the time we got there it had started to rain }\end{array}$ & Prepositions and Time reference \\
\hline Culture heritage & Cultural heritage & Word formation \\
\hline $\begin{array}{l}\text { DISCOURSE: } \\
\text { OPENING AND CLOSING } \\
\text { WERE AWKWARD }\end{array}$ & $\begin{array}{l}\text { SAYING HELLO. } \\
\text { It is my pleasure to be here today. } \\
\text { Today we are going to discuss. } \\
\text { I'd like to thank Sandra for the opportunity to speak } \\
\text { with you today about..... } \\
\text { SAYING GOODBYE } \\
\text { Well that's all I have today. I hope you enjoyed the } \\
\text { presentation. } \\
\text { I hope you find this glossary helpful. } \\
\text { Thanks for listening and I hope that you have gained } \\
\text { something from the presentation today. }\end{array}$ & $\begin{array}{l}\text { These are patterns that you take for granted in } \\
\text { your first language. } \\
\text { Practice modeling target structures within the } \\
\text { context. }\end{array}$ \\
\hline
\end{tabular}

We have chosen to highlight the utility of this information and as a direct consequence we are more interested in the relevance of this information for the trainee than to its posterior linguistic classification. Errors have been categorized using a contrastive grammar approach so that the instructor could learn from her own mistakes without having to understand previously the complex linguistic categories created for this purpose. These categories are interesting for linguistics, but not necessarily for learners, and even less so, if we are discussing non-language specialists. The errors illustrate one of the essential elements that we have established from the beginning. Imperfect performance is a part of CLIL implementation; and perhaps imperfect performance is a part of all teaching itself.

Clearly, in real time in the modality of spoken discourse more errors occur. The instructor who received this feedback has noted the relevance to her own professional development, not only as an English learner, but also with regard to proper communication strategies. Worthy of note is that intonation proved to be more significant than vocalic discrimination. In addition, syntax errors affected intelligibility more than lexical or word formation issues. Not only does the feedback uncover challenges such as pronunciation or specific syntactic usages, but also more discursive strategies like how to introduce oneself or to finish a presentation.

Certainly using this cooperative feedback has been insightful. In particular, the findings suggest an improved usage of rhetoric devices and interrogative syntax in general. The ability to reflect in a post hoc analysis allowed this professor to reflect on her own language proficiency.

\section{Conclusions and Recommendations}

EMI initiatives in higher education are on the increase across Europe. Conditions, however, are not optimal and programmes that are completely or partially taught in English are launched with no specific attention to quality assurance. Higher Education institutions should establish requirements and provide resources so that teaching quality is not compromised and students can benefit from language development possibilities (see Marsh et al., 2013). The university context requires a closer follow up, which indeed, has been the focus of this paper.

This study has dealt with the professional development of CLIL professors at the university level. Some universities find themselves in what Donald Schön calls a "squeeze-play": An educational institution in which educational policy plays a small role. "In the normative curriculum, a practicum comes last, almost as an afterthought. (Schön, 1987, pp. 310-311)" Very little has been written about professional development at this tertiary level, but many of the issues related to action research developed in other academic settings apply. Nevertheless, there are some specific considerations related to professionals in higher education, their needs and their expectations. No one seems to address the challenges of the multi-level classroom and we strongly recommend future research to pursue this area. Without the practical element, professional development in education is detached from the setting and the real challenges professors face every day. This study explored the question of whether participatory action research can provide meaningful experiences that add to good teaching practice through an 
in-service training. Griffith (2017) has called this developing the CLIL eye.

Some final reflections pertain to the evaluative information provided by both students and staff. Students perceive the need for some kind of language support and provision which the institution, however, fails to provide systematically. In addition, students tend to demand a high level of English competence from the teachers and they admit that learning through English also requires a high command of English from them. Both teachers and learners agree on the need to improve their proficiency in English. In order to teach and learn cognitively complex and demanding disciplinary content, a high level of proficiency is indispensable. The support needed necessarily must be created within each context as the needs vary, across student groups, within the staff as well as in regard to specific contents. In service training seems to readily adapt to each context and address needs as they occur.

Not surprisingly, research evidence suggests that limitations in language ability may hinder students from expressing and exploring complex concepts (Met \& Lorenz, 1997; Airey, 2009), and this conclusion is equally applicable to staff, who has also been found to face difficulties with non-subject related interactions and classroom management language (Dafouz \& Núñez, 2009; Strotmann et al., 2014). This coincides with our findings in that every bilingual programme discovers new ways to support language in its own unique search for quality.

Nevertheless, the question remains as to what is the appropriate benchmark for students and instructors. Although TOEFL 550 seems to be a common benchmark in some institutions (Marsh et al., 2013, p. 18), the target for staff to reach a CEF C1 seems entirely reasonable. At the UMA, top down planners suggest that a $\mathrm{B} 1$ for students and a B2 for instructors is sufficient. However, when the research moves directly into the classroom, all needs assessment suggest that $\mathrm{B} 2$ for students and a proficient $\mathrm{C} 1$ for instructors seems to be more advisable if quality instruction is to be considered. Language must consistently be supported through instructional design as well as is qualitative assessment for instructors. Top-down planners in their desire to encourage more instructors to teach through a second language, underestimate the challenges that this context inspires.

The first year experience of a partially English-taught bachelor's degree programme revealed major challenges regarding lack of integrated language provision and support, language competence level in students and staff, and mixed-level groups. In order to face these challenges, a collaborative interdisciplinary innovation project was initiated. In closing, we are fully convinced that no attempt to introduce a change in the medium of instruction will ever be successful if the teachers involved do not share, work together and collaborate in group discussions, needs identification and collective solutions. As we continue to seek quality instruction in our bilingual programme, we humbly feel we have taken a step in the right direction through this in-service training.

\section{Acknowledgements}

The research focus of this article includes a direct collaboration with the international $\mathrm{I}+\mathrm{D}$ project HAR2016-75662-P Subjectivity Practices in the Contemporary Arts. Critic Reception and Identity Fiction from Gender Perspective at Malaga University as well as with the Research Group: Linguistics and Applied Languages (LLA) HUM 842 Junta de Andalucía.

\section{REFERENCES}

[1] Airey, J. (2012). I don't teach language: The linguistic attitudes of physics lecturers in Sweden. In U. Smit and E. DaFouz (Eds.), AILA Review: Integrating Content and Language in Higher Education Amsterdam: John Benjamins Publishing Co. 25, 64-79.

[2] Barrios, E., López-Gutiérrez, A., Lechuga, C. (2016). Facing Challenges in English Medium Instruction through Engaging in an Innovation Project. Revista Procedia - Social and Behavioral Sciences. 228 (2016), pp. 209 - 214. ELSEVIER (Scopus).

[3] Brinton, D., Snow, M., \& Wesche, M. (2011). Content-Based Second Language Instruction. Ann Arbor: University of Michigan Press.

[4] Castro Garcés, Angela Yicely, and Liliana Martínez Granada. 2016. "The Role of Collaborative Action Research in Teachers' Professional Development." In PROFILE Issues in Teachers' Professional Development, 18(1), 3954.

[5] Coyle, D., Hood, P., \& Marsh, D. (2010). CLIL Content and Language integrated Learning. Cambridge University Press.

[6] Danto, A.C. (2003). Más allá de la Caja Brillo. Las artes visuales desde la perspectiva posthistórica [traducción, Alfredo Brotons Muñoz]. Madrid: AKAL

[7] Doiz, A., Lasagabaster, D., \& Sierra, J.M. (2013). Introduction. In A. Doiz, D. Lasagabaster, \& J.M. Sierra (Eds.), English-medium instruction at universities: Global challenges (pp. xvii-xxii). Bristol: Multilingual matters.

[8] Dafouz E., \& Núñez, B. (2009). CLIL in higher education: Devising a new learning landscape. In E. Dafouz M. Guerrini (Eds.), CLIL across Educational Levels: Experiences from Primary, Secondary and Tertiary Contexts (pp. 101- 112). Madrid: Richmond-Santillana.

[9] Dearden, Julie, 2014. "English as a Medium of Instruction a Growing Global Phenomenon." Executive Summary. British Council. Accessed March, 2018 from https://www.britishcouncil.org/sites/default/files/e484_emi --_cover_option_3_final_web.pdf.

[10] Fortanet, I. (2008). Questions for debate in English medium 
lecturing in Spain. In R. Wilkinson

[11] V. Zegers,V. (Eds.), Realizing Content and Language Integration in Higher Education (pp. 21-31). Maastricht: Maastricht University.

[12] Gajo, L. (2007). Linguistic knowledge and subject knowledge: how does bilingualism contribute to subject development? The International Journal of Bilingual Education and Bilingualism, 10 (5), 563-581.

[13] Griffith, M. (2012) CLIL and the Plurilingual University: Orientation for the Reluctant Professor. In Propuestas de actividades y metodológicas especificas para la mejora del bilingüismo en ingeniería. F. Manzano Agugliaro and A. García Cruz (Eds.). Almería: Universidad de Almería. $27-49$.

[14] Griffith, M. (2017) "Tapping into the intellectual capital at the University." Universal Journal of Educational Research Volumen. 5 (12A), 134-143 DOI: 10.13189/ujer.2017.051320.

[15] González-Sanz, M., Feliu-Torruella, M. \& Cardona-Gómez, G. (2017). Las Visual Thinking Strategies (VTS) desde la perspectiva del educador patrimonial. DAFO del método en su aplicación práctica $=$ Visual Thinking Strategies from the perspectives of museum educators': a SWOT analysis of the method's practical implementation. Revista de educación $\mathrm{n}^{\circ}$ 375, enero-marzo 2017, pp. 160-183.

[16] Gustafsson, M., \& Jacobs, C. (2013). Editorial: Student Learning and ICLHE-Frameworks and Contexts. Journal of Academic Writing, 3(1), ii-xii.

[17] Hynninen, N. (2012). ICL at the micro level: L2 speakers taking on the role of language experts. In U. Smit, \& E. Dafouz (Eds.), AILA review Amsterdam: John Benjamin Publishing Company. (25), 13-29.

[18] Klaassen, R. (2008). Preparing lecturers for English-medium instruction. In R. Wilkinson, \& V. Zegers, V. (Eds.), Realizing Content and Language Integration in Higher Education (pp. 32-42). Maastricht: Maastricht University.

[19] Lechuga, C. (2015). Paisaje Cultural: la imagen expandida en nuestro ideario procomún. Prácticas artísticas que usan el Patrimonio Cultural y Natural/Cultural Landscape: expanded image in our procomun thinking. Tesis Doctoral. $\mathrm{PhD}$ dissertation, co-directed by Dr Ignacio Henares and Isabel Garnelo. Department of History of Art. University of Granada (Spain). [Retrieved from http://hdl.handle.net/10481/40032 ]
[20] Lechuga, C. (2016). Reflective learning: contemporary art in gender studies Video. FACEDUMA. University of Málaga. [Retrieved from https://www.youtube.com/watch?v=FoFWOEKnCqA\&t=1 $44 \mathrm{~s}]$.

[21] Lorenzo, F. A. (2008). "Instructional Discourse in bilingual settings. An empirical study of linguistic adjustments in content and language integrated learning." Language Learning Journal, (36) 1: 21-33.

[22] Marsh, D., Pavón-Vázquez, V., \& Frigols-Martín, M.J. (2013). The higher education languages landscape: Ensuring quality in English language degree programmes. Valencia, Spain: Valencian International University.

[23] Met, M. \& Lorenz, E. B. (1997). Lessons from U.S immersion programs: Two decades of experience. In R.K. Johnson \& M. Swain (Eds.), Immersion education: International perspectives (pp. 243-264). Cambridge University Press, Cambridge, UK.

[24] Smit, U., \& Dafouz, E. (2012). AILA Review: Integrating Content and Language in Higher Education Amsterdam: John Benjamins Publishing Co. (25).

[25] Strotmann, B., Bamond, V., Lopez Lago, J. A., Bailen, M., Bonilla, S., \& Montesinos, F. (2014). Improving bilingual higher education: Training university professors in content and language integrated learning. Higher Learning Research Communications, 4(1), 91-97. http://dx.doi.org/10.18870/hlrc.v4i1.198

[26] Wächter, B. \& Maiworm, F. (2008). English-Taught Programmes in European Higher Education. The Picture in 2007. Bonn: Lemmens.

[27] Wilkinson, R., \& Zegers, V. (2008). Introduction. In R. Wilkinson \& V. Zegers (Eds.). Realizing content and language integration in higher education (pp. 1-9). Maastricht: Maastricht University.

[28] Wilkinson, R. (2013). English-medium instruction at a Dutch university: Challenges and pitfalls. In A. Doiz, D.

[29] Lasagabaster, \& J.M. Sierra (Eds.), English-medium instruction at universities: Global challenges Multilingual matters. Bristol: 3-24.

[30] UNESCO (1972). Convention concerning the Protection of the World Cultural and Natural Heritage 1972. Paris, 16 November 1972. [Retrieved from http://portal.unesco.org/en/ev.php-URL_ID=13055\&URL DO=DO_TOPIC\&URL_SECTION=201.html 